\title{
Christopher Max Hoshino, John V. Tiberi, and Thomas G. Harris: Orthopedic emergency and office procedures
}

\section{Lippincott, Williams \& Wilkins, Philadelphia, 2014, 179 pp, Paperback, \$74.99, ISBN: 13:978-1-4511-4370-6}

\author{
Alain G. Graftiaux
}

Received: 15 December 2014/Accepted: 28 December 2014/Published online: 6 March 2015

(C) Springer-Verlag France 2015

This book is intended to the students who seek a book with the format pocket that they always have at hand at the time to make an act.

This book wants to be practical taking again step by step the most common procedures at the same time for the emergency acts and the acts in consultation.

The first chapter deals with the general information on the installation of the plasters and splints, then follow the various chapters concerning the segments of members and articulations.

Each chapter explains the various possibilities of puncture and infiltration and averages the nonoperational ones of treatment in urgency of the fractures and dislocations.

The choice of the technique is then left to the reader.

This book is very practical with many drawings and photographs, as well as councils of use to facilitate the work of young people.

In addition an access online is provided.

Conflict of interest None.

A. G. Graftiaux (ه)

Strasbourg, France

e-mail: graftiaux.alain@neuf.fr 